\title{
Estimating the economic benefits of redeveloping the former Athens International Airport
}

\author{
D. Damigos \& E. Laliotis \\ National Technical University of Athens, Greece
}

\begin{abstract}
This paper illustrates the results of a survey carried out in order to evaluate two alternatives suggested for the redevelopment of the former Athens International Airport, a project known as "Hellenikon Metropolitan Park". The first plan provides for a mixed-use park involving both green areas with cultural, sports and leisure facilities and commercial uses that will offer a financial return. The second plan proposes solely the development of a green park with light recreational facilities. In order to examine the situation from a social point of view, the effect of the proposed plans to the property prices in the surrounding area is examined by means of the Fuzzy Delphi Method. The results indicate that although both plans will positively affect the price of dwellings in a similar influence zone, the second plan will create a premium almost $60 \%$ higher, compared to the first one. Although a clear answer can only be obtained through further research, the findings could be used in order to justify the evaluation of the proposed land-use alternatives.
\end{abstract}

Keywords: Fuzzy Delphi Method, property values, brownfields redevelopment, urban green areas.

\section{Introduction}

Since the mid-1980s, there has been a growing recognition that brownfields (i.e. former industrial sites, airports, railway stations, etc.) should not be solely seen as a problem (e.g. due to pre-existing historic contamination) but also as an opportunity for enhancing local development in a sustainable manner. The policies implemented so far intend primarily to lessen the costs and risks 
associated with the regeneration of brownfields. As a result, the vast majority of remediation efforts focus mainly on converting brownfields into productive uses (i.e. commercial, residential or even industrial).

Nevertheless, the creation of green space by reclaiming brownfields could provide significant social, environmental and economic benefits, e.g. air pollution control, noise attenuation, improvement of microclimate, provision of recreational opportunities, etc. [1]. For this reason there exists a widening interest to support this type of development, especially within urban boundaries. For example, between 1988 and 1993, over 19\% of brownfield sites in Britain were converted into green areas [2]. However, the costs of redeveloping the derelict land can be assessed in a straightforward way but the benefits of noncommercial uses, i.e. green areas, are hard to estimate in monetary terms. Thus, they are often overlooked in decision-making procedures. In order to confront this situation, the use of environmental economics has been proved to be beneficial, since several research efforts have established that green spaces provide monetary benefits in many different ways [3-6], and especially through the increase of surrounding property values [7-10].

This paper highlights the abovementioned issues through an illustrative case, namely the reuse of the former Athens International Airport. More specifically, two redevelopment alternatives of the so-called "Hellenikon Metropolitan Park" project are evaluated on the basis of results obtained by estimating the effect of the proposed plans to the property prices in the surrounding area. Towards this aim, the Fuzzy Delphi Method, a well-established group judgment technique, is applied in order to overcome some of the theoretical and practical complexities of the Hedonic Pricing analysis.

\section{Methodological background}

\subsection{The hedonic approach}

The hedonic pricing method is a well established approach for estimating the effect of environmental quality on housing values, especially in the urban setting. According to the theoretical concept of the method, dwelling prices differ with respect to housing characteristics (square footage, number of rooms, quality of accommodation, etc.), neighbourhood characteristics (level and quality of social infrastructure, housing density, traffic, etc.) and the quality of the environment (air quality, noise level, landscape features, etc.). Other characteristics being equal, it would be reasonable to expect that properties in areas with better environmental quality enjoy higher prices. The hedonic method has been used in a variety of applications in order to reveal the monetary value of environmental attributes such as: clean air, proximity to green areas and open spaces, view to lakes and forests, noise levels, etc., e.g. [7-9, 11, 12].

The application of the method prerequisites the availability of extensive cross-section data, time series data or a mixture of both concerning real prices and characteristics of dwellings in the area of interest, in order to isolate the 
contribution of the environmental factor to the market price by means of econometric techniques. In addition, data should be collected from a reasonably stable market period [13]. Further issues arise with respect to model specification and level of disaggregation, market distortions, etc. [13-15]. Finally, it should be mentioned that the method cannot be easily applied when potential changes on the environmental quality are investigated, thus it is mainly used in ex post analyses.

\subsection{The Fuzzy Delphi Method}

Due to the lack of adequate datasets, the instability of housing market in Greece during the previous years and the fact that the hedonic analysis cannot be applied in ex ante cases, an alternative approach was adopted, namely the Fuzzy Delphi Method (FDM).

The FDM is an analytical process based on the Delphi Method and the theory of fuzzy sets [16]. The theoretical assumptions and methodological procedures of the Delphi method were developed in the 1950s and 1960s at the RAND Corporation, at Santa Monica, California [17, 18]. The method is actually a structured process for the systematic collection and collation of judgments from a group of experts on a particular issue, by means of a series of questionnaires interspersed with controlled opinion feedback [19]. The experts are requested to give their opinion separately and independently about the variables in question. The results of the first round are analyzed statistically by finding their average and are then interspersed to the participants, who are asked if they wish to revise their earlier estimates. This process is followed again and again until the outcome converges to a reasonable solution from the point of view of the decision maker.

In order to deal with the effect of subjectivity of the experts, as well as the uncertainty imposed by the complexity of the problems studied, the theory of fuzzy sets, known also as fuzzy logic, is usually involved in the context of the FDM [20]. Fuzzy sets are an extension of the classical set theory. A fuzzy set is characterized by a membership-degree function, which maps the members of the Universe into the unit interval $[0,1]$. The value 0 means that the member is not included in the given set, 1 describes a fully included member. Hence, for the universe $\boldsymbol{U}$ a fuzzy set $\boldsymbol{A}$ is defined by as:

$$
\left.\boldsymbol{A}=\left\{x, \mu_{A}(x)\right) \mid x \in \boldsymbol{A}, \mu_{A}(x) \in[0,1]\right\}
$$

where $\mu_{A}(x)$ is the membership-degree function $\mu: \mathrm{x} \rightarrow[0 ; 1]$.

A fuzzy number is defined in the universe $\boldsymbol{R}$ as a convex and normalized fuzzy set. In this case, the triangular numbers were considered to be mostly suitable, since they could be constructed easily by asking the experts to specify three values, the minimum, the maximum, and the most plausible. More specifically, the triangulated fuzzy number $\boldsymbol{T}$ with membership function $\mu_{A}(x)$ is defined on $\boldsymbol{R}$, as follows: 


$$
\boldsymbol{T}=\left\{\begin{array}{c}
\mathrm{x}-\mathrm{a} / \mathrm{b}-\mathrm{a} \\
\mathrm{x}-\mathrm{c} / \mathrm{b}-\mathrm{c} \\
0
\end{array}\right\} \begin{gathered}
\mathrm{a} \leq \mathrm{x} \leq \mathrm{b} \\
\mathrm{b} \leq \mathrm{x} \leq \mathrm{c} \\
\text { otherwise }
\end{gathered}
$$

where $[\boldsymbol{a}, \boldsymbol{c}]$ is the supporting interval and the point $(\boldsymbol{b}, \boldsymbol{1})$ is the peak.

The Fuzzy Delphi Method consists of the following steps [21]:

Step 1. The experts $E_{i}, i=1,2, \ldots, n$, are asked to provide their estimates on the particular subject, determining the minimum $\alpha_{1}{ }^{(i)}$, the most plausible $a_{M}{ }^{(i)}$ and the maximum $\mathrm{a}_{2}{ }^{(\mathrm{i})}$. The data given by the experts $E i$ are presented in the form of triangular numbers:

$$
A_{i}=\left(a_{1}{ }^{(i)}, a_{M}^{(i)}, a_{2}{ }^{(i)}\right), i=1,2, \ldots, n
$$

Step 2. The fuzzy average $A_{a v e}=\left(m_{1}, m_{M}, m_{2}\right)$ of all $A_{i}$ is estimated, according to the equation:

$$
A_{a v e}=\left(m_{1}, m_{M}, m_{2}\right)=\left(\frac{1}{n} \sum_{i=1}^{n} a_{1}{ }^{(i)}, \frac{1}{n} \sum_{i=1}^{n} a_{m}{ }^{(i)}, \frac{1}{n} \sum_{i=1}^{n} a_{2}{ }^{(i)}\right)
$$

Next, for each expert the deviation between $A_{\text {ave }}$ and $A_{i}$, is computed, which is a triangular number defined by:

$$
\begin{gathered}
\mathrm{A}_{\mathrm{ave}}-\mathrm{A}_{\mathrm{i}}=\left(\mathrm{m}_{1}-\mathrm{a}_{1}{ }^{(\mathrm{i})}, \mathrm{m}_{\mathrm{M}}-\mathrm{a}_{\mathrm{M}}{ }^{(\mathrm{i})}, \mathrm{m}_{2}-\mathrm{a}_{2}{ }^{(\mathrm{i})}\right)= \\
\left(\frac{1}{\mathrm{n}} \sum_{\mathrm{i}=1}^{\mathrm{n}} \mathrm{a}_{1}{ }^{(\mathrm{i})}-\mathrm{a}_{1}{ }^{(\mathrm{i})}, \frac{1}{\mathrm{n}} \sum_{\mathrm{i}=1}^{\mathrm{n}} \mathrm{a}_{\mathrm{m}}{ }^{(\mathrm{i})}-\mathrm{a}_{\mathrm{m}}{ }^{(\mathrm{i})}, \frac{1}{\mathrm{n}} \sum_{\mathrm{i}=1}^{\mathrm{n}} \mathrm{a}_{2}{ }^{(\mathrm{i})}-\mathrm{a}_{2}{ }^{(\mathrm{i})}\right)
\end{gathered}
$$

The deviation $A_{a v e}-A_{i}$ is given back to the experts for revision.

Step 3. Each expert $E_{i}$ gives a new triangular number:

$$
\mathrm{B}_{\mathrm{i}}=\left(\mathrm{b}_{1}{ }^{(\mathrm{i})}, \mathrm{b}_{\mathrm{M}}{ }^{(\mathrm{i})}, \mathrm{b}_{2}{ }^{(\mathrm{i})}\right), \mathrm{i}=1,2, \ldots, \mathrm{n}
$$

This process, starting with step 2, is repeated, until two successive means become reasonably close, according to the decision maker.

The Delphi approach has been criticized for dependency of forecasts on the particular judges selected, the sensitivity of results to ambiguity in the questionnaire and the difficulty in assessing the degree of expertise incorporated into the forecast $[22,23]$. Nevertheless, several studies indicate high agreement between the Delphi estimates and the real numbers [24, 25].

\section{Case study}

\subsection{The former Athens International Airport site}

The former Athens International Airport, known as "Hellinikon International Airport" was built in 1938. The site, located $11.5 \mathrm{~km}$ south from the centre of Athens, covers an area of 530 hectares and borders residential areas, the Gulf of Saronikos and the Glyfada Golf Club (Fig. 1). 


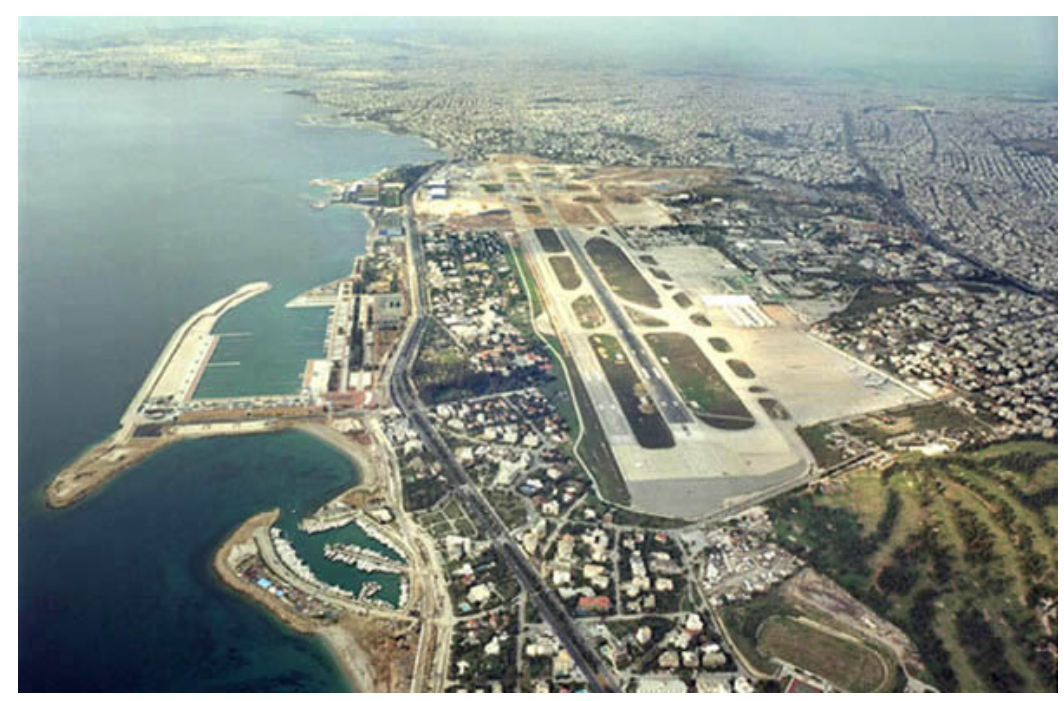

Figure 1: The former "Athens International Airport" (Source: SERERO architects).

In 1950 the airport had already equipped with two runways of $2,250 \mathrm{~m}$ in length. By the end of 50's the Airport handled 500,000 passengers and 4,000 tonnes of cargo per year and the main runway extended to $3,500 \mathrm{~m}$ to accommodate traffic growth and jet aircrafts. Having predicted that the airport would handle up to 2,400,000 passengers annually by 1968, a new Terminal, known as the East Air Terminal, was built. The East Air Terminal, designed by the Finnish-American architect E. Saarinen, opened in 1969. In the early 70's the Airport handled 3,300,000 passengers and 25,000 tonnes of cargo per year. In 1997 the number of passengers reached 12,000,000, while the cargo volume handled was 120,000 tonnes. The passenger traffic was increasing rapidly and it was evident that the Airport could not meet future demand since the surrounding residential area prohibited any further expansion. Thus, a new study was commissioned aimed at the relocation of the Airport. In March 2001, after an uninterrupted operation of 60 years, the Athens International Airport was finally moved to a new location, at Spata, where the new "Eleftherios Venizelos" Airport was built [25].

\subsection{The redevelopment of the site}

After its closure, a portion of the airport was redeveloped, hosting the venues for basketball, fencing, canoe/kayak slalom, field hockey, baseball and softball during the 2004 Summer Olympics. Nowadays, the "Hellenikon Complex", covering an area of about 80 hectares, is managed by the "Hellenic Olympic Properties S.A.”, a state-owned enterprise. The complex currently comprises six sport grounds and two training facilities. An area of about 20 hectares in the East Air Terminal is administered by the "Hellenic Tourism Development Co.", a 
state-owned enterprise, as well. Furthermore, an area of about 11 hectares is used as tram and bus depot and 5.5 hectares have been given away to local entities. Finally, the area includes 419 buildings, of which 126 belong to the Civil Aviation Authority. Although the northern and western portions of the site have changed, the Athens radar centre is located there and part of the old airport and its runways still exist at an area of about 300 hectares.

Since the termination of operations of "Hellinikon International Airport" in the end of March 2002 and especially after the 2004 Summer Olympics, there have been discussions concerning the reuse of airport's facilities. In June 2006, the Greek Minister for the Environment, Physical Planning and Public Works announced a final draft plan known as "Hellenikon Metropolitan Park", according to which 400 hectares will be converted to a park, while 100 hectares will be used to accommodate housing and office facilities.

It is referred that the proposed plan will create the largest urban park in Europe and will enhance the standards of living conditions of Athens' inhabitants. In total, green areas and amenity spaces will exceed 550 hectares, given that the plan also foresees: (a) the construction of an underground road tunnel for the adjacent Poseidonos Avenue that will allow the connection of the park with the beachfront and (b) the demolition of 378 out of the 419 buildings of the old airport. Regarding building development, the plan involves a business zone of 65 hectares and a residential zone of 35 hectares, respectively. Furthermore, a new museum of modern art is also planned. In total, it is estimated that built-up areas will cover 26 hectares, while the rest surface will be provided for public/common uses and infrastructure. It is envisage that the state will earn 500 million Euros from selling this area to land developers. This amount will fund the "Hellenikon Metropolitan Park" project, as well as the creation of smaller parks in devastated areas of Athens.

Nevertheless, representatives from municipalities surrounding the park and other entities accused the government of handing over a large chunk of privileged land to developers. In addition, they argued that the proposed plan, instead of the metropolitan park announced, will create a new city with a population of 15,000 - 20,000 people. Therefore, they formulated and counter proposed an alternative plan involving solely the development of a green park with light recreational facilities. This plan will establish additionally $30-100$ hectares of green space (depending on the final design of the built area proposed by the first plan). On the other hand, the cost of the project will be totally covered by the state.

Considering that the city of Athens presents an unacceptable rate of proportional green space per capita, both plans will improve the quality of urban environment, though at a different level. From a social point of view, the critical question is whether or not 100 hectares of green space worth 500 million Euros that will be earned from developing an equivalent portion of the site. However, in order to answer this question the alternatives should be compared on an equal basis, i.e. the environmental and socio-economic benefits offered by the additional green space should be monetized. 


\subsection{Survey characteristics}

In order to provide land-use planners and decision-makers with some useful pieces of information, the monetary benefits derived from the redevelopment alternatives were estimated by means of the Fuzzy Delphi Method. Towards this direction, a panel consisting of ten real estate experts, namely realtors, was employed. The participants' background in terms of professional skills and experience was taken into consideration, in order to maximize the effectiveness of the study. Panellists were provided with guidelines to increase the reliability of their answers and they were told that they were free to add their comments.

The experts were provided with a specially formed questionnaire, in order to give their estimates for the effect of each redevelopment alternative on the price of dwellings located in the vicinity. The questionnaire consisted of a comprehensive list of twenty eight questions. The first set included questions regarding the effect of the airport, while it was operating. More specifically, the experts were asked to state their estimations with respect to: (a) the effect of the airport on dwellings prices (positive or negative), (b) the influence zone of the airport (in $\mathrm{km}$ ), and (c) the change in average dwelling price (in percentage) within the influence zone. The second set referred to the influence of the termination of operations of the "Hellinikon Airport" on the surrounding housing market, using a similar set of three questions, as described above. The third set of questions investigated the "announcement effect" of airport's development. The experts were provided with the same set of questions, in order to determine the effect of the announcement in terms of influence range and price alteration. The final set of questions focused on a hypothetical case. The panellists were asked to forecast the effects of each of the proposed alternatives on the housing market of the neighbouring area with respect to the zone of influence of each alternative on the dwelling price (in $\mathrm{km}$ ) and the premium attracted by a typical dwelling located in the zone of influence (in percentage)

It should be noted that the answers given by the experts regarding the questions of the first three sets derived from market data, while those provided to the final set of the questionnaire were based on estimates. Given the scope of the paper, only the results referred to the last part of the questionnaire, i.e. the effect of the proposed alternatives, are presented in the next section.

\subsection{Results}

The survey was completed in two rounds, since the point of diminishing returns was considered to be satisfying. For conciseness reasons, only the results of the second round are presented.

According to the results, the Alternative A proposed by the state will influence, on average, the surrounding lodgings on a range up to $3 \mathrm{~km}$ and will modify their value between $11 \%-33 \%$, with the most probable rate being $23 \%$. The implementation of Alternative B, which is counter proposed by local entities, is expected to affect the dwelling prices at the same range, i.e. up to 3 $\mathrm{km}$. A dwelling within this zone, however, will attract, on average, a premium of 
Table 1: $\quad$ Influence zone (in $\mathrm{km})$.

\begin{tabular}{ccccccc}
\hline $\mathbf{E}_{\mathbf{i}}$ & $\mathbf{A}_{\min }$ & $\mathbf{A}_{\text {likelv }}$ & $\mathbf{A}_{\max }$ & $\mathbf{B}_{\min }$ & $\mathbf{B}_{\text {likely }}$ & $\mathbf{B}_{\max }$ \\
\hline E1 & 0 & 2 & 4 & 0 & 1 & 2 \\
E2 & 0 & 2 & 3 & 0 & 2 & 3 \\
E3 & 0 & 2 & 3 & 0 & 2 & 3 \\
E4 & 0 & 1 & 2 & 0 & 1 & 2 \\
E5 & 0 & 1 & 2 & 0 & 2 & 2 \\
E6 & 0 & 2 & 3 & 0 & 2 & 2 \\
E7 & 1 & 2 & 4 & 0 & 1 & 2 \\
E8 & 0 & 1 & 2 & 1 & 2 & 3 \\
E9 & 0 & 1 & 2 & 0 & 1 & 2 \\
E10 & 0 & 1 & 2 & 0 & 1 & 2 \\
\hline Average & $\mathbf{0}$ & $\mathbf{2}$ & $\mathbf{3}$ & $\mathbf{0}$ & $\mathbf{2}$ & $\mathbf{3}$ \\
Minimum & $\mathbf{0}$ & $\mathbf{1}$ & $\mathbf{1}$ & $\mathbf{0}$ & $\mathbf{1}$ & $\mathbf{2}$ \\
Maximum & $\mathbf{1}$ & $\mathbf{2}$ & $\mathbf{4}$ & $\mathbf{1}$ & $\mathbf{2}$ & $\mathbf{3}$ \\
\hline
\end{tabular}

Table 2: $\quad$ Price alteration (in percentage).

\begin{tabular}{ccccccc}
\hline $\mathbf{E}_{\mathbf{i}}$ & $\mathbf{A}_{\min }$ & $\mathbf{A}_{\text {likely }}$ & $\mathbf{A}_{\max }$ & $\mathbf{B}_{\min }$ & $\mathbf{B}_{\text {likelv }}$ & $\mathbf{B}_{\max }$ \\
\hline E1 & 10 & 20 & 30 & 15 & 35 & 50 \\
E2 & 10 & 20 & 30 & 25 & 35 & 60 \\
E3 & 10 & 30 & 35 & 25 & 30 & 40 \\
E4 & 20 & 35 & 50 & 20 & 30 & 40 \\
E5 & 5 & 15 & 20 & 20 & 50 & 70 \\
E6 & 5 & 15 & 30 & 15 & 30 & 50 \\
E7 & 10 & 20 & 30 & 20 & 30 & 50 \\
E8 & 15 & 25 & 40 & 20 & 35 & 40 \\
E9 & 15 & 25 & 35 & 20 & 40 & 60 \\
E10 & 10 & 20 & 30 & 25 & 40 & 60 \\
\hline Average & $\mathbf{1 1 \%}$ & $\mathbf{2 3 \%}$ & $\mathbf{3 3 \%}$ & $\mathbf{2 1 \%}$ & $\mathbf{3 6 \%}$ & $\mathbf{5 2 \%}$ \\
Minimum & $\mathbf{5 \%}$ & $\mathbf{1 5 \%}$ & $\mathbf{2 0 \%}$ & $\mathbf{1 5 \%}$ & $\mathbf{3 0 \%}$ & $\mathbf{4 0 \%}$ \\
Maximum & $\mathbf{2 0 \%}$ & $\mathbf{3 5 \%}$ & $\mathbf{5 0 \%}$ & $\mathbf{2 5 \%}$ & $\mathbf{5 0 \%}$ & $\mathbf{7 0 \%}$ \\
\hline
\end{tabular}

$21 \%$ up to $52 \%$, and most probably up to $36 \%$. The results indicate that although both plans will positively affect the price of dwellings in a similar range, the second plan will create a premium almost $60 \%$ higher, compared to the first one.

Given that in year 2006 the average unit price of a dwelling in the area of interest was 3,000 Euro/sq.m, the added value to the properties is estimated to 690 Euros/sq.m and 1,080 Euros/sq.m for the first and the second alternative, respectively. These figures amount to 69,000 Euros and 108,000 Euros, correspondingly, for a typical apartment in the surroundings (saleable area: 100 sq.m.). 


\section{Discussion}

Taking into account the findings of the study, it would be logically assumed that the monetary benefits attributed to the additional green space are not sufficient to justify the trade-off of selling the area to land developers. Given that the difference in the additional premium attracted by a dwelling between the two alternatives is 39,000 Euros, the second plan should influence approximately 13,000 apartments. This figure certainly exceeds the total number of residences located within the influence zone. Furthermore, it should be also considered that this added value could be detached only by means of a special property tax in a depth of time.

On the other hand, however, the economic benefits of urban forests are not restricted to the increase in property value. For example, the energy savings of buildings due to the impact of urban parks to the microclimate are also significant, considering that savings on cooling costs for a typical household have been estimated at $1.9 \%$ to $2.5 \%$ per residential tree [3]. McPherson [26] estimated that an urban park of 210 hectares in Chicago provided air pollution reductions equivalent to traditional emission controls costing 136 USD per day, while another study indicated that the annual aggregate value of stormwater management of the existing tree cover of the USA cities, in 1997, was 400 billion USD [27]. In addition to those findings, several studies indicate significant use and non-use values associated with urban forests. In Finland, for instance, researchers found that households were willing to pay an amount of 14.4-27.2 Euros per year in order to prevent the conversion of urban forests to another land use [4]. In Spain, people were willing to pay an annual tax of 71 Euros in order to construct an urban park of 28 hectares in the centre of Valencia, on the site of an old train station [28]. In the city of Athens, households were willing to pay an annual fee of 41.5 Euros in order to establish a forestry organization for maintaining and enhancing city's green spaces [29].

Urban parks and green spaces are subject to development pressure because their benefits are hard to estimate in economic terms. In the case of "Hellenikon Metropolitan Park", the results definitely prove that even a 'pure' green area would create significant economic value for the society. Thus, although a final answer to the critical question can only be gained through further research, these findings should be taken into account in order to come up with a more sound and socially fair solution with respect to the proposed land-use alternatives.

\section{References}

[1] Commission of the European Communities (CEC), Green Paper on the Urban Environment, COM(90) 218 Final, Brussels, 27 June, 1990.

[2] De Souza, C., Turning brownfields into green space in the City of Toronto, Landscape and Urban Planning, 62(4), pp. 181-198, 2003.

[3] Simpson, E.G. and McPherson, J.R., Simulation of Tree Shade Impacts on Residential Energy Use for Space Conditioning in Sacramento, Atmospheric Environment, 32(1),pp. 69-74, 1998. 
[4] Tyrväinen, L. and Väänänen, H., The economic value of urban forest amenities: an application of the contingent valuation method, Landscape and Urban Planning. 43(1-3), pp. 105-118, 1998.

[5] Damigos, D. and Kaliampakos, D., Assessing the benefits of reclaiming urban quarries: a CVM analysis, Landscape and Urban Planning, 64(4), pp. 249-258, 2003.

[6] Nowak, D.J. and Dwyer, J.F., Understanding the benefits and costs of urban forest ecosystems. In: Kuser, J., ed. Urban and community forestry in the Northeast, 2nd edition, Springer, the Netherlands, pp. 25 - 46, 2007.

[7] Anderson, L.M., and Cordell, H.K., Influence of trees on residential property values in Athens, Georgia (U.S.A.): A survey based on actual sales prices, Landscape and Urban Planning, 15(1-2), pp. 153-164, 1988.

[8] Tyrväinen, L. and Miettinen, A., Property prices and urban forest amenities, Journal of Environmental Economics and management, 39, pp. 205-233, 2000.

[9] Luttik, J., The value of trees, water and open space as reflected by house prices in the Netherlands, Landscape and Urban Planning, 48(3-4), pp. 161-167, 2000.

[10] Damigos, D. and Kaliampakos, D., Forecasting the effects of environmental changes on residential land prices: An application of Fuzzy Delphi Method, Thirteenth Annual Conference of EAERE, June 25-28 ${ }^{\text {th }}$, Budapest, Hungary, 2004.

[11] Rosen, S., Hedonic prices and implicit markets: product differentiation in pure competition, Journal of Political Economy, 82, pp. 34-55, 1974.

[12] Nelson, J.P., Highway noise and property values: a survey of recent evidence. Journal of Transport Economics and Policy, XIC, pp. 37-52, 1982.

[13] Kula, E. Economics of Natural Resources, the Environment and Policies, Chapman and Hall, London, U.K., 1994.

[14] Butler, R.V., The specification of housing indexes for urban housing, Land economics, 58, pp. 96 - 108, 1982.

[15] Palmquist, R.B., Hedonic methods. In: Measuring the demand for environmental quality, Braden, J.B. and Kolstad, C.D. eds. North-Holland, Amsterdam, pp. 77-120, 1991.

[16] Zadeh, L., Fuzzy Sets and Applications: Selected Papers. John Wiley \& Sons, New York, 1987.

[17] Dalkey, N. and Helmer, O., An Experimental Application of the Delphi Method to the Use of Experts, The RAND Corporation, Santa Monica, California, USA, 1962.

[18] Dalkey, N., The Delphi Method: An Experimental Study of Group Opinion, RM-5888-PR, The RAND Corporation, Santa Monica, California, USA, 1969.

[19] Adler, M. and Ziglio, E., Gazing into the Oracle: The Delphi Method and its Application to Social Policy and Public Health, Philadelphia: Taylor and Francis, 264 p., 1996. 
[20] Kaufman, A. and Gupta, M.M., Fuzzy Mathematical Models in Engineering and Management Sciences, North-Holland, Amsterdam, 1988.

[21] Bojadziev, G. and Bojadziev, M., Fuzzy Logic for Business, Finance and Management, Word Scientific Publishing, Singapore, pp. 22-23, 1997.

[22] Sackman, H., Delphi Assessment: Expert Opinion, Forecasting, and Group Process, The RAND Corporation, Report \#R-1283-PR, Santa Monica, California, USA, 1974.

[23] Madridakis, S. and Wheelwright, S.C., Interactive Forecasting, Univariate and Multivariate Methods, Second Edition. Holden-Day. San Francisco, 1978.

[24] Milkovich, G., Anthony A. and Thomas M., The Use of Delphi Procedures in Manpower Forecasting, Management Science, 19(4), pp. 381-388, 1972.

[25] Air Traffic Safety Electronic Engineers Association of Hellenic Civil Aviation Authority, Athens International Airport History, http://www.hcaa-eleng.gr/athhist.htm\#English

[26] McPherson, E.G., Environmental benefits and costs of the urban forest, in Rodell. P.D., (ed.) Proceedings of the Fifth National Urban Forest Conference, Los Angeles, Washington, DC, American Forestry Association, pp. 52-54, 1991.

[27] American Forests, The State of Our Urban Forests: Assessing Tree Cover and Developing Goals, White paper Washington, D.C., 1997.

[28] del Saz Salazar S. and Menéndez G, Estimating the non-market benefits of an urban park: Does proximity matter? Land Use Policy, 24(1), pp. 296305, 2007.

[29] Kalavrytinos, N. and Damigos, D., The Economic Value of Urban Green Spaces in the Attica Basin, Technica Chronica Scientific Journal, Technical Chamber of Greece, II, 1-2, pp. 7-21, 2006. 